\title{
Perinevic dermatosis neglecta: clinical and dermoscopic description ${ }^{*}$
}

\author{
Vincenzo Piccolo ${ }^{1}$, Teresa Russo ${ }^{1}$, Lilian Mathias Delorenze ${ }^{1}$, Giuseppe Argenziano ${ }^{1}$
}

DOI: http:/ / dx.doi.org/10.1590/abd1806-4841.20197980

\begin{abstract}
Perinevic dermatosis neglecta is an underestimated skin condition usually affecting children and adolescents, characterized by the appearance of dirt-like brownish pigmentation around a preexisting nevus and often a matter of concern for parents. We describe the clinical and dermoscopic findings in a case of perinaevic dermatosis neglecta and discuss the possible etiology of this phenomenon.
\end{abstract}

Keywords: Dermatology; Dermoscopy; Pediatrics

Dear Editor,

We recently saw a 12-year-old boy who was referred to our clinic for evaluation of a "sudden" change in a preexisting nevus on the neck, characterized by perinevic hyperpigmentation (Figure 1A). His parents reported that he had avoided washing the area because he was afraid of injuring the nevus. Dermoscopy showed a cobblestone-arranged accumulation of pigmented keratin (previously described as "cornflake-like") surrounding a clear-cut benign dermal nevus, promptly supporting the diagnosis of 'perinevic dermatosis neglecta' (PDN) (Figure 1B). ${ }^{1}$ After accurate alcohol swabbing, the hyperpigmentation disappeared both on clinical and dermoscopic examination (Figures 2A-B).

Although dermatosis neglecta $(\mathrm{DN})$ and terra firma-forme dermatosis (TFFD) have been thoroughly described in the literature, no information has been published on the existence of PDN. ${ }^{1-3}$ We thus take the opportunity to discuss PDN, a likely underdiagnosed and underreported skin condition, usually affecting children or adolescents, who may avoid washing around a dermal nevus for fear of touching or injuring it. Two factors may help explain this strange phenomenon. First, the myth that traumatized nevi turn into melanomas, which may make people more cautious when scrubbing their skin around dermal nevi. ${ }^{4}$ The second factor is age-related: when children and adolescents begin assuming responsibility for their own bodily cleanliness, they tend to be less monitored by their parents and thus could also be less observant of their personal hygiene. Alcohol swabbing and parents' reassurance are the best management strategies in PDN. Dermoscopy of TFFD and DN have been described recently, underlining the usefulness of dermoscopy
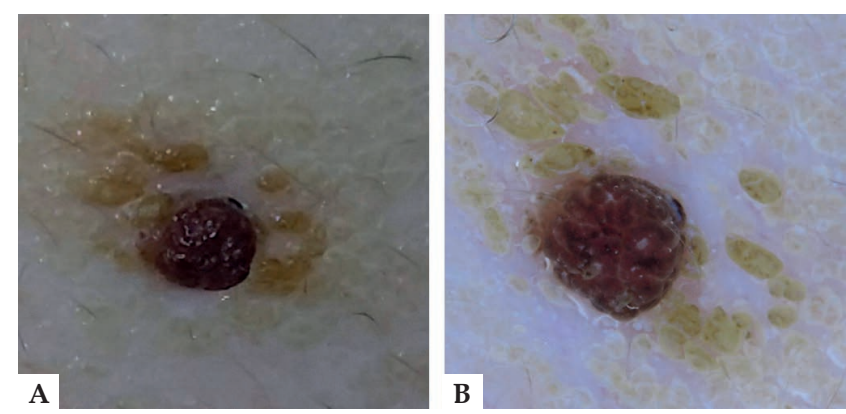

FIGURE 1: A - Hyperpigmented patch surrounding a melanocytic lesion on the neck; B - Dermoscopy showing the cornflake-like appearance of the keratin around the dermal nevus
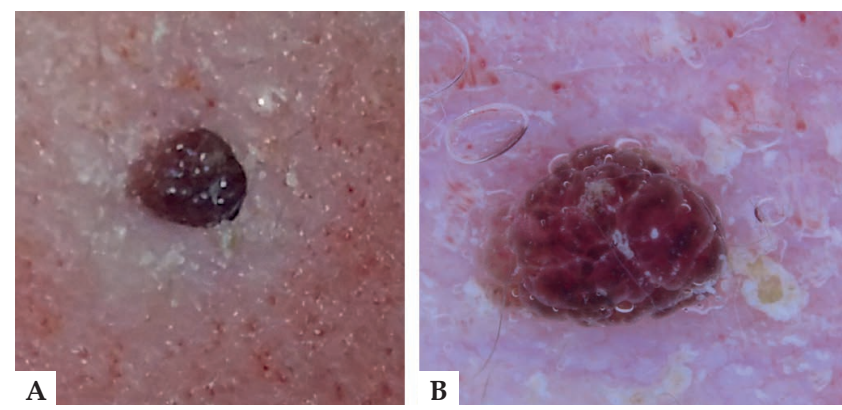

Figure 2: A - Disappearance of the perinevic dermatosis neglecta after careful alcohol swabbing; B - Dermoscopy after alcohol swabbing fails to show the previously visible perinevic hyperpigmentation. The dotted vessels found in the perilesional skin are due to irritation from the alcohol

\footnotetext{
Received 15 December 2017.

Accepted 23 March 2018.

Work conducted at the Dermatology Unit, University of Campania, Naples, Italy.

Financial support: None.

Conflict of interest: None.

1 Dermatology Unit, University of Campania, Naples, Italy.
}

MAILING AdDRESS:

Vincenzo Piccolo

E-mail: piccolo.vincenzo@gmail.com

(C)2019 by Anais Brasileiros de Dermatologia 
for the diagnosis. ${ }^{1}$ However, to the best of our knowledge, no data have been published in the literature on PDN or its dermoscopic appearance.

Most melanocytic lesions in children and adolescents are benign and easy to diagnose, although a few worrisome and problemat- ic lesions do exist and must be recognized. ${ }^{5,6} \mathrm{PDN}$ represents a benign nevus-associated cutaneous condition, and dermatologists should be aware of the existence of this skin disorder, whose recognition on the basis of clinical and dermoscopic features is important to avoid unnecessary excisions of melanocytic nevi with unusual appearance.

\section{REFERENCES}

1. Errichetti E, Stinco G. Dermoscopy in terra firma-forme dermatosis and dermatosis neglecta. Int J Dermatol. 2017;56:1481-3.

2. Greywal T, Cohen PR. Non-invasive methods to establish the diagnosis of terra firma-forme dermatosis: The SMART (Skin Modified by Alcohol Rubbing Test) evaluation and dermoscopy. Dermatol Online J. 2016;22. pii:13030/qt7jk6k6d9. Aslan NÇ, Güler Ş, Demirci K, Isiyel E. Features of Terra Firma-Forme Dermatosis. Ann Fam Med. 2018:16:52-4.
4. Piccolo V, Russo T, Giacomel J, Lallas A, Alfano R, Argenziano G. Dispelling myths concerning pigmented skin lesions. J Eur Acad Dermatol Venereol. 2016;30:919-25. Moscarella E, Piccolo V, Argenziano G, Lallas A, Longo C, Castagnetti F, et al. Problematic lesions in children. Dermatol Clin. 2013;31:535-47.

6. Piccolo V, Moscarella E, Zalaudek I, Ferrara G, Picciocchi R, Ametrano 0, et al. Analysis of clinical and dermoscopic features in melanocytic lesions with special emphasis on problematic lesions in children. Expert Rev Dermatol. 2013;8:155-70.

\section{AUTHORS'CONTRIBUTIONS}

Vincenzo Piccolo

(iD) ORCID

0000-0001-7798-4368

Approval of the final version of the manuscript, Conception and planning of the study, Elaboration and writing of the manuscript, Obtaining, analyzing and interpreting the data, Intellectual participation in propaedeutic and/or therapeutic conduct of the cases studied, Critical review of the literature, Critical review of the manuscript
Teresa Russo
(iD) ORCID
0000-0003-1792-9716

Approval of the final version of the manuscript, Elaboração e redação do manuscrito, Obtaining, analyzing and interpreting the data, Critical review of the manuscript

Lilian Mathias Delorenze $\quad$ (iD) ORCID 0000-0003-3677-6989

Approval of the final version of the manuscript, Elaboration and writing of the manuscript

Giuseppe Argenziano $\quad$ (iD) ORCID 0000-0003-1413-8214

Approval of the final version of the manuscript, Conception and planning of the study, Critical review of the literature, Critical review of the manuscript

How to cite this article: Piccolo V, Russo T, Delorenze LM, Argenziano G. Perinevic dermatosis neglecta: clinical and dermoscopic description. An Bras Dermatol. 2019;94(3):361-2. 